\title{
ANALISIS DAYA DUKUNG DAN PENURUNAN PONDASI TIANG BOR PADA PROYEK PEMBANGUNAN GEDUNG K UNIVERSITAS MUHAMMADIYAH PURWOKERTO
}

\section{ANALYSIS OF BEARING CAPACITY AND SETTLEMENT OF BORE PILE FOUNDATIONS IN K BUILDING PROJECT UNIVERSITY OF MUHAMMADIYAH PURWOKERTO}

\author{
Rizqa Zain ${ }^{1}$, Amris Azizi', M. Agus Salim ${ }^{3}$ \\ Program Studi S1 Teknik Sipil, Fakultas Teknik dan Sains \\ Universitas Muhammadiyah Purwokerto
}

\section{Informasi Artikel \\ Dikirim, \\ Direvisi, \\ Diterima,}

\section{Korespondensi Penulis:}

\section{Rizqa Zain}

Program Studi Teknik Sipil Universitas Muhammadiyah Purwokerto

JL. K.H. Ahmad Dahlan

Purwokerto, 53182

Email: rizqozayn@gmail.com

\begin{abstract}
ABSTRAK
Pondasi merupakan bagian penting dari suatu bangunan sipil, pondasi sebagai dasar penahan beban terdasar dari suatu konstruksi. Pondasi bertugas meletakkan bangunan dan meneruskan beban bangunan atas ke dasar tanah yang cukup kuat mendukungnya. Tujuan dari penelitian ini untuk menghitung daya dukung dan penurunan tiang bor, dimana kapasitas daya dukung pondasi dihitung berdasarkan data SPT dengan menggunakan 2 Metode yaitu Metode Meyerhoff dan Metode Reese \& Wright. Dari hasil Analisa dan perhitungan daya dukung tiang kedalaman $18 \mathrm{~m}$, diameter $\mathrm{d} 1=0,4 \mathrm{~m}$ dan diameter $\mathrm{d} 2=0,6 \mathrm{~m}$. Berdasarkan Metode Meyerhoff, daya dukung tiang tunggal (Qull) sebesar Qu1 = 902,674 ton dan Qu2 = 466,6 ton, sedangkan menggunakan Metode Reese \& Wright daya dukung tiang tunggal (Qull) sebesar Qu1 = 474,884 ton dan Qu2 = 296,107 ton. Dari analisa data Shop Drawing dan As Built Drawing dan perhitungan ulang beban aksial menggunakan Etabs 19, cek aman beban aksial yang di pikul oleh bore pile dengan Metode Meyerhoff maupun Metode Reese \& Wright setelah dilakukan perbandingan dengan daya dukung izin tiap kelompok, seluruh pondasi tiang bor mampu menahan beban yang bekerja diatasnya, sehingga pondasi dikategorikan aman (Qall > Pp). Perbandingan daya dukung ijin tiang sebesar 1:0,639. Penurunan pondasi yang terjadi pada setiap tiang dikatagorikan aman karena penurunan tidak lebih besar dari penurunan maksimum yang diizinkan.
\end{abstract}

Kata Kunci : Tiang bor, beban aksial, daya dukung, penurunan

\section{ABSTRACT}

The foundation is an important part of a civil building, the foundation as the basis for bearing the most basic loads of a construction. A strong foundation lays the building and the load on the building to the ground that is sufficient to support it. The purpose of this study is to calculate the bearing capacity and lowering of the drill pile, where the bearing capacity of the foundation is based on SPT data using 2 methods, namely the Meyerhoff method and the Reese \& Wright method. From the analysis and calculation of the pile bearing capacity with a depth of $18 \mathrm{~m}$, diameter $d 1=0.4 \mathrm{~m}$ and diameter $d 2=$ $0.6 \mathrm{~m}$. Based on the Meyerhoff method, the single pile bearing capacity (Qull) is Qu1 = 902,674 tonnes and Qu2 $=466.6$ tonnes, while using the Reese \& Wright method the single pile bearing capacity (Qull) is Qu1 $=474,884$ tonnes and Qu2 $=296,107$ tonnes From the data analysis Shop Drawing and As Built Drawing and axial load calculations using Etabs 19, check the axial load carried by the bore pile with the Meyerhoff Method or the Reese \& Wright Method after comparisons with the permit carrying capacity of each group, all drill pile foundations are able to withstand loads who work on it, so that the foundation is categorized as safe (Qall> Pp). Comparison of the allowable bearing capacity of the pile is 1: 0.639. The settlement that occurs on each pile is categorized as safe because the settlement is not greater than the maximum allowable settlement.

Keyword : bored pile, axial load, bearing capacity, settlement 


\section{PENDAhuluan}

Struktur bangunan merupakan suatu hal yang sangat vital dalam ilmu sipil, yang mana merupakan suatu alat utama dalam pembangunan bangunan primer. Struktur bangunan pada umumnya terdiri dari struktur bawah dan struktur atas. Struktur bawah sendiri yang dimaksud adalah struktur bangunan yang berada di dalam tanah, sedangkan struktur atas yaitu struktur yang berada diatas tanah. Struktur bawah dari suatu bangunan lazim disebut pondasi, pondasi ini bertugas meletakkan bangunan dan meneruskan beban bangunan atas (upper structure/super structure) ke dasar tanah yang cukup kuat mendukungnya.

Pondasi merupakan bagian penting dari suatu bangunan sipil, pondasi sebagai dasar penahan beban terdasar dari suatu konstruksi. Jalan, gedung, jembatan, bendungan, dan kontruksi sipil lainnya tanpa pondasi yang kuat pasti akan mengalami kegagalan kontruksi.

Oleh karena itu dalam pengaplikasiannya, struktur bawah sangat diperhitungkan dalam merencanakan sebuah pondasi sehingga proses pemindahan beban bangunan ke tanah dasar dapat berlangsung dengan baik dan aman. pada perencanaan pondasi harus mempertimbangkan beberapa persyaratan, yaitu :

1. Daya dukung tanah harus lebih besar untuk dapat menerima beban dari pondasi.

2. Pondasi harus cukup kuat untuk mencegah penurunan (settlement) dan perputaran (rotasi) yang berlebihan.

3. Tidak terjadi penurunan setempat yang terlalu besar bila dibandingkan dengan penurunan pondasi di dekatnya.

4. Cukup aman terhadap bahaya guling.

Analisis mengenai daya dukung pondasi penting dilakukan karena apabila kekuatan tanah tidak mampu memikul beban pondasi maka penurunan yang berlebihan atau keruntuhan dari tanah akan terjadi. Jenis pondasi yang digunakan dalam proyek pembangunan Gedung K Universitas Muhammadiyah Purwokerto ini adalah pondasi tiang bor.

Dari permasalahan tersebut diatas maka penulis melihat bahwa penelitian terhadap daya dukung tanah dan penurunan pondasi ini merupakan satu hal yang menarik, karena merupakan hal yang paling fundamental dalam sebuah proyek. Khususnya peninjauan yang dilakukan terhadap proyek Pembangunan Gedung K Universitas Muhammadiyah Purwokerto ini.

Gedung ini terdiri dari 10 lantai dengan konstruksi bawah dan atas merupakan beton bertulang. Untuk pondasi utama menggunakan pondasi Tiang Bor.

Penelitian ini bertujuan untuk mengetahui daya dukung tanah dan penurunan pondasi pada Proyek Gedung K Universitas Muhammadiyah Purwokerto dengan menggunakan data pondasi, shop drawing, asbuilt drawing serta hasil analisis pembebanan.

\section{METODE PENELITIAN}

\subsection{Objek Penelitian}

Objek penelitian ini dilakukan di Proyek Pembangunan Gedung K, bangunan ini terletak di Kampus I, Universitas Muhammadiyah Purwokerto, Jalan KH. Ahmad Dahlan, Kelurahan Dukuhwaluh, Kecamatan Kembaran, Kabupaten Banyumas, Provinsi Jawa Tengah. Gedung ini diperuntukkan untuk sarana pendidikan dilingkungan Universitas Muhammadiyah Purwokerto, dan mulai di bangun pada awal 2019 dan sampai saat melakukan penelitian pengerjaan pembangunan Gedung K Universitas Muhammadiyah Purwokerto sudah selesai.

Gedung ini memiliki luas bangunan 11544,75 m2, terdiri dari 10 lantai dengan konstruksi bawah beton bertulang dan konstruksi atap rangka baja. Untuk pondasi utama menggunakan pondasi tiang bor sedalam $18 \mathrm{~m}$ dengan diameter $0,6 \mathrm{~m}$ sebanyak 243 buah dan diameter $0,4 \mathrm{~m}$ sebanyak 5 buah.

\subsection{Jenis Penelitian}

Jenis penelitian ini tergolong dalan penelitian kuantitatif, dengan menganalisis pondasi tiang bor yang menjadi patokan di lapangan. Sehingga dapat diperoleh nilai daya dukung tanah dan besaran penurunan yang terjadi di dasar pondasi, untuk disimpulkan pondasi tersebut stabil terhadap beban struktur diatasnya.

\subsection{Tahap Penelitian}

\subsubsection{Survey Pendahuluan}

Kegiatan-kegiatan yang dilakukan dalam tahap ini pada dasarnya untuk mengidentifikasi ketersediaan sarana pendukung dalam melakukan penelitian ini. Hal-hal tersebut meliputi pemilihan lokasi studi, ketersediaan data, ketersediaan literatur atau pustaka.

\subsubsection{Metode Perolehan Data}

Berikut adalah cara mendapatkan data antara lain sebagai berikut :

1. Tinjauan Langsung (Data Primer)

CIVeng Vol.2, No.2, Juli $2021: 59 \sim 68$ 
Metode ini dilakukan secara langsung meninjau lokasi proyek dan melakukan wawancara dengan pengawas yang ada di lokasi.

2. Studi Literatur (Data Sekunder)

Tahap ini diawali dengan penelusuran kepustakaan, mengenai analisis yang akan dibuat serta mempelajarinya yang berkaitan dengan metode penelitian yang digunakan.

Data-data yang digunakan sebagai dasar penelitian berupa data :

a. As Built Drawing Gedung K Universitas Muhammadiyah Purwokerto

b. Data perencanaan struktur atas

c. Data pengujian tanah.

\subsection{Analisis Data}

Ada beberapa data yang harus dianalisis guna mencapai hasil atau tujuan yang ingin didapat, yaitu mengetahui kapasitas daya dukung pondas tiang bor dan penurunan pondasi. Berikut data-data yang akan dianalisis, yaitu :

1. Menganalisis dsitribusi beban aksial menggunakan ETABS v.19 dengan berdasar pada gambar rencana.

2. Menganalisis daya dukung tiang bor melalui data hasil uji SPT (Standard Penetration Test) dan gambar detail pondasi.

3. Menganalisis daya dukung tiang bor kelompok dengan data daya dukung ultimit yang sudah diperoleh dari analisis daya dukung tiang bor, gambar denah pondasi dan gambar detail pondasi. Analisa dilakukan menggunakan Metode Meyerhoff dan Metoder Reese \& Wright.

4. Menganalisis daya dukung ijin tiang bor kelompok dengan data daya dukung tiang kelompok yang dibagi dengan faktor aman sebesar 2 .

5. Mengecek keamanan pondasi dengan syarat daya dukung ijin tiang bor harus lebih besar dari beban aksialnya.

6. Mengecek penurunan yang terjadi pada pondasi tiang bor. Dengan syarat penurunan yang terjadi tidak lebih besar dari penurunan ijinnya.

\section{HASIL DAN PEMBAHASAN}

\subsection{Data Tanah}

Berdasarkan kondisi tanah yang diperoleh dari laporan hasil penyelidikan tanah Pelaksana Soil Investigation \& Survey Topography PT. Tribina Wahana Cipta, melalui tes SPT (Standard Penetration Test) didapat data sebagi berikut :

Tabel 1. Hasil Uji SPT (DB-01)

\begin{tabular}{ccc}
\hline Kedalaman $(\mathrm{m})$ & Jenis Tanah & N-SPT \\
\hline $0,00-3,00$ & Soft silty clay & 3 \\
$3,00-6,00$ & Medium dense silty clay & 14 \\
$6,00-8,00$ & Medium dense sand trace gravel & 15 \\
$8,00-10,00$ & Dense sandy gravel & 15 \\
$10,00-12,00$ & Very dense sandy gravel & 60 \\
$12,00-14,00$ & Loose silty sandy gravel & 5 \\
$14,00-16,00$ & Very dense sandy silt trace gravel & 60 \\
$16,00-30,03$ & Very dense sandy gravel & 60 \\
\hline
\end{tabular}

Tabel 2. Hasil Uji SPT (DB-02)

\begin{tabular}{ccc}
\hline Kedalaman $(\mathrm{m})$ & Jenis Tanah & N-SPT \\
\hline $0,00-4,00$ & Medium silty clay trace sand & $4-5$ \\
$4,00-6,00$ & Medium dense silty sand trace gravel & 29 \\
$6,00-8,00$ & Medium dense sandy silty & 23 \\
$8,00-10,00$ & Dense sandy gravel & 41 \\
$10,00-20,12$ & Very dense sandy gravel & 60 \\
\hline
\end{tabular}

Sumber : Hasil Uji SPT, 2017

Kedalaman pondasi tiang bor rencana adalah $18 \mathrm{~m}$. 


\subsection{Data Struktur}

Data struktur diperoleh dari data sekunder yang terdiri dari struktur bangunan bawah dan struktur bangunan atas. Pada struktur bangunan bawah menggunakan pondasi tiang bor dengan penampang lingkaran diameter $0,60 \mathrm{~m}$ sebanyak 243 buah dan diameter $0,40 \mathrm{~m}$ sebanyak 5 buah dengan kedalaman $18 \mathrm{~m}$ dengan mutu beton K-350. Dari data sekunder yang diperoleh, dalam perencanaan pondasi tiang bor ini ada beberapa tipe pondasi berdasarkan jumlah pondasi dalam pile capnya, yaitu :

Tabel 3. Data Tipe Pondasi

\begin{tabular}{cc}
\hline Tipe & Jumlah Pondasi \\
\hline P1 & 1 \\
P4 & 4 \\
P5 & 5 \\
P6 & 6 \\
P15 & 15 \\
P30 & 30 \\
P35 & 35 \\
\hline Sumber : Gambar Struktur, 2019
\end{tabular}

\subsection{Analisis Distribusi Gaya Pada Tiang}

Analisis distribusi gaya pada tiang dilakukan dengan menggunakan program komputer struktur dan analisis ETABS. Dengan memperhatikan Asbuilt Drawing proyek pembangunan Gedung K Universitas Muhammadiyah Purwokerto, peneliti mendefinisikan setiap material, mulai dari kolom, balok, shearwall dan plat. Setelah material didefinisikan maka selanjutnya adalah input pembebanan dan kombinasi pembebanan sesuai dengan SNI 8460-2017 Persyaratan Perancangan Geoteknik.

Material yang telah didefinisikan dengan mutu beton K350, fc'30 MPa, dan fy $490 \mathrm{Mpa}$, kemudian mulai di input pada lembar kerja ETABS sesuai dengan gambar rencana inputkan bebannya. Setelah selesai untuk diinput maka lakukan analisis dengan kombinasi pembebanan 1,2 DL, 1,2 SDL, dan 1,6 LL untuk mengetahui beban aksialnya. Adapun beban aksial hasil analisis melalui ETABS adalah sebagai berikut:

Tabel 4. Beban Aksial

\begin{tabular}{cccccc}
\hline Nomor Tiang & Jumlah Tiang & Pp (ton) & Nomor Tiang & Jumlah Tiang & Pp (ton) \\
\hline 1 & 1 & 23,69 & 20 & 6 & 666,35 \\
2 & 1 & 25,04 & 21 & 6 & 636,79 \\
3 & 15 & 756,88 & 22 & 6 & 628,61 \\
4 & 6 & 604,98 & 23 & 6 & 633,73 \\
5 & 6 & 645,17 & 24 & 6 & 642,30 \\
6 & 6 & 650,70 & 25 & 5 & 622,57 \\
7 & 6 & 708,05 & 26 & 15 & 762,25 \\
8 & 6 & 713,09 & 27 & 6 & 588,78 \\
9 & 6 & 694,09 & 28 & 6 & 528,11 \\
10 & 5 & 475,43 & 29 & 30 & 830,36 \\
11 & 4 & 553,52 & 30 & 6 & 526,06 \\
12 & 6 & 658,47 & 31 & 6 & 620,56 \\
13 & 6 & 655,41 & 32 & 5 & 465,02 \\
14 & 6 & 655,32 & 33 & 1 & 10,37 \\
15 & 6 & 656,24 & 34 & 1 & 10,76 \\
16 & 6 & 658,11 & 35 & 1 & 11,49 \\
17 & 5 & 633,13 & & & \\
18 & 35 & 873,83 & & & \\
19 & 4 & 551,99 & & &
\end{tabular}

\subsection{Analisis Daya Dukung}

Untuk mengetahui besaran daya dukung tiang pancang penulis menggunakan analisis Metode Meyerhof dan Reese and Wright, dengan memasukkan data hasil uji SPT dengan memperhatikan gambar struktur.

\subsubsection{Daya Dukung Ujung Tiang Bor}

Perhitungan daya dukung ujung tiang Bor $(\mathrm{Qp})$ dihitung sebesar : 
1. Metode Meyerhoff

$$
\mathrm{Qb}=40 . \mathrm{Nb} \cdot \mathrm{Ab}
$$

Dimana :

$\mathrm{Qb}=$ Daya dukung ujung tiang (ton)

$\mathrm{Nb}=$ Nilai rata-rata statistik dari bilangan-bilangan SPT dalam daerah kira-kira 8B di atas sampai dengan 4B di bawah titik tiang.

$\mathrm{Ab}=$ Luas penampang pile.

Jadi, daya dukung ujung tiang bor $(\mathrm{Qb})$ adalah :

$\mathrm{Qb} 1=672$ ton dan $\mathrm{Qb} 2=312$ ton

2. Metode Reese \& Wright

$$
\mathrm{Qb}=\mathrm{qP} \cdot \mathrm{Ap}
$$

Dimana :

$Q \mathrm{~b}=$ Daya dukung ujung tiang (ton)

$\mathrm{qP}=$ Tahanan ujung per satuan luas (ton/m2)

$\mathrm{Ap}=$ Luas penampang tiang bor $(\mathrm{m} 2)$

Jadi, daya dukung ujung tiang bor $(\mathrm{Qb})$ adalah :

$\mathrm{Qb} 1=107,639$ ton dan $\mathrm{Qb2}=49,975$ ton

\subsubsection{Daya Dukung Selimut Tiang Bor}

Dengan memperhatikan hasil dari pengujian tanah menggunakan metode SPT pada kedalaman rencana pondasi yaitu $18 \mathrm{~m}$ tanah non kohesif (berpasir), perhitungan daya dukung selimut tiang bor (Qs) dihitung sebesar:

1. Metode meyerhoff

$$
\mathrm{Qs}=\mathrm{Xm} \text {. N-SPT . P . Li }
$$

Dimana :

$\mathrm{Xm}=0,2$ untuk bore pile

$\mathrm{Li}=$ Panjang lapisan tanah $(\mathrm{m})$

$\mathrm{P}=$ Keliling tiang $(\mathrm{m})$

$\mathrm{N}=$ Banyaknya perhitungan pukulan rata-rata statistic

Jadi, daya dukung selimut tiang bor (Qs) adalah :

Qs1 $=230,674$ ton dan $\mathrm{Qs} 2=154,6$ ton

2. Metode Reese \& Wright

$$
Q s=\sum_{i=1}^{n} \quad \text { fs.L.P }
$$

Dimana :

fs = gesekan selimut tiang per satuan luas (ton $/ \mathrm{m} 2)$

a $=$ factor adhesi

$\mathrm{Cu}=$ kohesi tanah $(\operatorname{ton} / \mathrm{m} 2)$

Qs = daya dukung ultimit selimut tiang (ton)

$\mathrm{L} \quad=$ panjang tiang $(\mathrm{m})$

$\mathrm{P}=$ keliling tiang

Jadi, daya dukung selimut tiang bor (Qs) adalah :

$\mathrm{Qs} 1=367,245$ ton dan Qs2 $=246,132$ ton

\subsubsection{Daya Dukung Ultimit Tiang Bor}

Perhitungan daya dukung ultimit tiang $(\mathrm{Qu})$ dihitung sebesar :

$$
\mathrm{Qu}=\mathrm{Qb}+\mathrm{Qs}
$$


Tabel 5. Daya Dukung Ultimit Tiang Bor

\begin{tabular}{cccc}
\hline \multicolumn{2}{c}{ Metode Meyerhoff } & \multicolumn{2}{c}{ Metode Reese \& Wright } \\
\hline Qul (ton) & Qu2 (ton) & Qul (ton) & Qu2 (ton) \\
\hline 902,674 & 466,6 & 474,884 & 296,107 \\
\hline Sumber : Hasil Perhitungan, 2021 & & &
\end{tabular}

\subsection{Analisis Daya Dukung Tiang Bor Kelompok}

Perhitungan daya dukung ultimit tiang kelompok didapat mengkalikan efisiensi kelompok tiang. Sehingga sebelum menghitung daya dukungnya adalah menghitung terlebih dahulu menghitung efisiensi tiang dengan menggunakan persamaan :

$$
E g=1-\left(\frac{(n-1) m+(m-1) n}{90 m n}\right) \theta
$$

Dari persamaan tersebut didapat jumlah yang berbeda dari masing masing tipe, karena jumlah tiang merupakan variabel dari persamaan tersebut.

Tabel 6. Efisiensi Tiang

\begin{tabular}{ccc}
\hline Tipe Pondasi & Jumlah Pondasi & Efisiensi tiang \\
\hline Tipe P1 & 1 & 1 \\
Tipe P4 & 4 & 0,99 \\
Tipe P5 & 5 & 0,99 \\
Tipe P6 & 6 & 0,99 \\
Tipe P15 & 15 & 0,99 \\
Tipe P30 & 30 & 0,99 \\
Tipe P35 & 35 & 0,99 \\
\hline Sumber $:$ Analisis Perhitungan, 2021
\end{tabular}

Selanjutnya adalah analisis daya dukung ultimit tiang kelompok dengan persamaan :

$$
\text { Qug = Qut x n Eg }
$$

Dimana :

Qug = Daya dukung tiang kelompok (ton)

$\mathrm{n}=$ Jumlah tiang

$\mathrm{Eg}=$ Efisiensi grup tiang

Qut $=$ Daya dukung ultimit tiang (ton)

Maka didapat daya dukung untuk masing-masing tipe pondasi pada tabel dibawah ini :

Tabel 7. Daya Dukung Ultimit Tiang Kelompok

\begin{tabular}{cccc}
\hline \multirow{2}{*}{ Tipe } & \multirow{2}{*}{ Jumlah Tiang } & \multicolumn{2}{c}{ Qg } \\
\cline { 3 - 4 } & & Meyerhoff & Reese \& Wright \\
\hline P1 & 1 & 466,6 & 296,107 \\
P4 & 5 & 3574,59 & 1880,541 \\
P5 & 6 & 4468,24 & 2350,676 \\
P6 & 15 & 5361,88 & 2820,811 \\
P15 & 30 & 13404,71 & 7052,027 \\
P30 & 35 & 26809,42 & 14104,055 \\
P35 & & 31277,65 & 16454,731 \\
\hline Sumber : Analisis Perhitungan, 2021 & & &
\end{tabular}

\subsection{Analisis Kapasitas Daya Dukung Ijin Tiang Bor Kelompok}

Daya dukung ijin tiang pancang kelompok didapat dari daya dukung ultimit tiang kelompok dibagi dengan faktor aman bangunan. Faktor aman yang digunakan adalah 2,0 karena tiang tanpa ada pembesaran dibagian bawahnya. Adapun persamaannya sebagai berikut :

$$
\text { Qall }=\frac{Q u}{S F}
$$


Hasil analisis, dapat dilihat pada tabel berikut :

Tabel 8. Daya Dukung Ijin Tiang

\begin{tabular}{ccc}
\hline \multirow{2}{*}{ Tipe } & \multicolumn{2}{c}{ Qall } \\
\cline { 2 - 3 } & Meyerhoff & Reese \& Wright \\
\hline Tipe P1 & 233,3 & 149,054 \\
Tipe P4 & 1787,295 & 940,271 \\
Tipe P5 & 2234,12 & 1175,338 \\
Tipe P6 & 2680,94 & 1410,406 \\
Tipe P15 & 6702,355 & 3526,014 \\
Tipe P30 & 13404,71 & 7052,028 \\
Tipe P35 & 15638,825 & 8227,366 \\
\hline
\end{tabular}

Sumber : Analisis Perhitungan, 2021

\subsection{Cek Aman Pondasi}

Syarat pondasi aman adalah daya dukung ijin harus lebih besar dari beban yang bekerja diatasnya (Qall > Pp). Apabila beban aksial lebih besar maka pondasi dikatakan tidak aman dan perlu di desain ulang.

Berikut adalah perbandingan antara daya dukung ijin tiang dengan beban aksialnya :

Tabel 9. Cek Aman Pondasi

\begin{tabular}{|c|c|c|c|c|c|c|c|c|c|}
\hline \multicolumn{5}{|c|}{ Metode Meyerhoff } & \multicolumn{5}{|c|}{ Metode Reese \& Wright } \\
\hline $\begin{array}{c}\text { Nomor } \\
\text { Tiang }\end{array}$ & $\begin{array}{c}\text { Tipe } \\
\text { Tiang }\end{array}$ & Qall & $\mathrm{Pp}$ & Keterangan & $\begin{array}{c}\text { Nomor } \\
\text { Tiang }\end{array}$ & $\begin{array}{c}\text { Tipe } \\
\text { Tiang }\end{array}$ & Qall & $\mathrm{Pp}$ & Keterangan \\
\hline 1 & 1 & 233,3 & 23,69 & Aman & 1 & 1 & 149,054 & 23,69 & Aman \\
\hline 2 & 1 & 233,3 & 25,04 & Aman & 2 & 1 & 149,054 & 25,04 & Aman \\
\hline 3 & 15 & 6702,355 & 756,88 & Aman & 3 & 15 & 3526,014 & 756,88 & Aman \\
\hline 4 & 6 & 2680,94 & 604,98 & Aman & 4 & 6 & 1410,406 & 604,98 & Aman \\
\hline 5 & 6 & 2680,94 & 645,17 & Aman & 5 & 6 & 1410,406 & 645,17 & Aman \\
\hline 6 & 6 & 2680,94 & 650,7 & Aman & 6 & 6 & 1410,406 & 650,7 & Aman \\
\hline 7 & 6 & 2680,94 & 708,05 & Aman & 7 & 6 & 1410,406 & 708,05 & Aman \\
\hline 8 & 6 & 2680,94 & 713,09 & Aman & 8 & 6 & 1410,406 & 713,09 & Aman \\
\hline 9 & 6 & 2680,94 & 694,09 & Aman & 9 & 6 & 1410,406 & 694,09 & Aman \\
\hline 10 & 5 & 2234,12 & 475,43 & Aman & 10 & 5 & 1175,338 & 475,43 & Aman \\
\hline 11 & 4 & 1787,295 & 553,52 & Aman & 11 & 4 & 940,271 & 553,52 & Aman \\
\hline 12 & 6 & 2680,94 & 658,47 & Aman & 12 & 6 & 1410,406 & 658,47 & Aman \\
\hline 13 & 6 & 2680,94 & 655,41 & Aman & 13 & 6 & 1410,406 & 655,41 & Aman \\
\hline 14 & 6 & 2680,94 & 655,32 & Aman & 14 & 6 & 1410,406 & 655,32 & Aman \\
\hline 15 & 6 & 2680,94 & 656,24 & Aman & 15 & 6 & 1410,406 & 656,24 & Aman \\
\hline 16 & 6 & 2680,94 & 658,11 & Aman & 16 & 6 & 1410,406 & 658,11 & Aman \\
\hline 17 & 5 & 2234,12 & 633,13 & Aman & 17 & 5 & 1175,338 & 633,13 & Aman \\
\hline 18 & 35 & 15638,83 & 873,83 & Aman & 18 & 35 & 8227,366 & 873,83 & Aman \\
\hline 19 & 4 & 1787,295 & 551,99 & Aman & 19 & 4 & 940,271 & 551,99 & Aman \\
\hline 20 & 6 & 2680,94 & 666,35 & Aman & 20 & 6 & 1410,406 & 666,35 & Aman \\
\hline 21 & 6 & 2680,94 & 636,79 & Aman & 21 & 6 & 1410,406 & 636,79 & Aman \\
\hline 22 & 6 & 2680,94 & 628,61 & Aman & 22 & 6 & 1410,406 & 628,61 & Aman \\
\hline 23 & 6 & 2680,94 & 633,73 & Aman & 23 & 6 & 1410,406 & 633,73 & Aman \\
\hline 24 & 6 & 2680,94 & 642,3 & Aman & 24 & 6 & 1410,406 & 642,3 & Aman \\
\hline 25 & 5 & 2234,12 & 622,57 & Aman & 25 & 5 & 1175,338 & 622,57 & Aman \\
\hline 26 & 15 & 6702,355 & 762,25 & Aman & 26 & 15 & 3526,014 & 762,25 & Aman \\
\hline 27 & 6 & 2680,94 & 588,78 & Aman & 27 & 6 & 1410,406 & 588,78 & Aman \\
\hline 28 & 6 & 2680,94 & 528,11 & Aman & 28 & 6 & 1410,406 & 528,11 & Aman \\
\hline 29 & 30 & 13404,71 & 830,36 & Aman & 29 & 30 & 7052,028 & 830,36 & Aman \\
\hline 30 & 6 & 2680,94 & 526,06 & Aman & 30 & 6 & 1410,406 & 526,06 & Aman \\
\hline 31 & 6 & 2680,94 & 620,56 & Aman & 31 & 6 & 1410,406 & 620,56 & Aman \\
\hline 32 & 5 & 2234,12 & 465,02 & Aman & 32 & 5 & 1175,338 & 465,02 & Aman \\
\hline 33 & 1 & 233,3 & 10,37 & Aman & 33 & 1 & 149,054 & 10,37 & Aman \\
\hline 34 & 1 & 233,3 & 10,76 & Aman & 34 & 1 & 149,054 & 10,76 & Aman \\
\hline 35 & 1 & 233,3 & 11,49 & Aman & 35 & 1 & 149,054 & 11,49 & Aman \\
\hline
\end{tabular}


Dari hasil analisis didapat bahwa semua pondasi mampu menahan beban yang bekerja diatasnya. Sehingga pondasi dikategorikan aman.

\subsection{Analisis Penurunan Tiang Tunggal}

Berdasarkan analisis daya dukung sebelumnya dan data struktur tiang bor yang diperloeh dari gambar struktur sebagai acuan perhitungan. Persamaan untuk menghitung penurunan tiang adalah sebagai berikut :

$$
S=\frac{D}{100}+\frac{Q \cdot L}{A b \cdot E b}
$$

Dimana :

$\mathrm{Ab}=$ luas penampang tiang $(\mathrm{m} 2)$

$\mathrm{D}=$ diameter tiang $(\mathrm{m})$

$\mathrm{Eb}=$ modulus elastisitas tiang (ton/m2)

$\mathrm{L}$ = panjang tiang yang tertanam (m)

$\mathrm{S}$ = penurunan total kepala tiang (m)

$\mathrm{Q}$ = daya dukung ujung tiang (ton)

Jadi, penurunan tiang akibat beban yang tersalur sepanjang batang $(\mathrm{S})$ yang terjadi adalah :

Tabel 10. Hasil Penurunan Tiang

\begin{tabular}{cccc}
\hline Metode Meyerhoff & \multicolumn{3}{c}{ Metode Reese \& Wright } \\
\hline $\mathrm{S} 1(\mathrm{~cm})$ & $\mathrm{S} 2(\mathrm{~cm})$ & $\mathrm{S} 1(\mathrm{~cm})$ & $\mathrm{S} 2(\mathrm{~cm})$ \\
\hline 2,23 & 2,10 & 0,8 & 0,7 \\
\hline Sumber : Analisis Perhitungan, 2021 & & &
\end{tabular}

Dari hasil analisis penurunan pondasi dikategorikan aman, karena penurunan pondasi lebih kecil dari penurunan ijin $(\mathrm{S}<\mathrm{Sijin})$. Sijin $=2,54 \mathrm{~cm}$ untuk bangunan umum.

\section{KESIMPULAN}

Berdasarkan hasil analisis daya dukung dan penurunan pondasi tiang bor pada proyek pembangunan Gedung K Universitas Muhammadiyah Purwokerto dapat diambil kesimpulan sebagai berikut :

1. Berdasarkan perhitungan efisiensi dan daya dukung izin (Qijin) didapat Q gabungan dengan Metode Meyerhoff didapat $\mathrm{P} 1=233,3$ ton $, \mathrm{P} 4=1787,295$ ton $, \mathrm{P} 5=2234,12$ ton $, \mathrm{P} 6=2680,94$ ton, $\mathrm{P} 15=$ 6702,355 ton, P30 = 13404,71 ton, dan P35 = 15638,825 ton. Dengan menggunakan Metode Reese \& Wright didapat Q gabungan P1 = 149,054 ton, P4 = 940,271 ton, $\mathrm{P} 5=1175,388$ ton, $\mathrm{P} 6=1410,406$ ton, $\mathrm{P} 15$ 3526,014 ton, $\mathrm{P} 30=7052,028$ ton, dan P35 = 8227,366 ton. Setelah dilakukan perbandingan dengan gaya aksial yang bekerja di atasnya, maka daya pondasi dihitung berdasarkan Metode Meyerhoff dan Reese \& Wright mampu menahan beban yang ada diatasnya (Qall > Pp).

2. Perbandingan daya dukung ijin tiang dengan meggunakan metode Meyerhoff dan Reese \& Wright sebesar 1:0,639.

3. Penurunan yang terjadi pada pondasi tiang bor dengan Metode Meyerhoff yaitu $\mathrm{S} 1=2,23 \mathrm{~cm}$ dan $\mathrm{S} 2=2,10$ $\mathrm{cm}$ sedangkan untuk Metode Resse \& Wright $\mathrm{S} 1=0,8 \mathrm{~cm}$ dan $\mathrm{S} 2=0,7 \mathrm{~cm}$. Penurunan pondasi yang terjadi pada setiap tiang dikatagorikan aman karena penurunan tidak lebih besar dari penurunan maksimum yang diizinkan yaitu $2,54 \mathrm{~cm}$ untuk bangunan umum.

\section{DAFTAR PUSTAKA}

[1] Albusoda, B. S., Mohammed S. M., dan Mohammad F. Abbas. (2020). Comparison among Different Methods to Estimate Ultimate Capacity of Bored Pile. Journal of IOP Conference Series: Materials Science and Engineering . 901 : 012008 .

[2] Bowles, J. E. (1993). Analisis dan Disain Pondasi 2, Edisi Kedua. Jakarta: Erlangga.

[3] Fadilah, U. N, dan Halimah Tunafiah. (2018). Analisa Daya Dukung Pondasi Bored Pile Berdasarkan Data N-Spt Menurut Rumus Reese \& Wright Dan Penurunan. Jurnal IKRA-ITH Teknologi, vol 2.3.

[4] Halibu, E. Z. (2015). Perencanaan Pondasi Bored Pile Dan Metode Pelaksanaan Pada Proyek Pembangunan Gedung Rsj Prof Dr. V.L. Ratumbuysang Manado. Manado: Politeknik Negeri Manado.

[5] Tobing, D. L. (2019). Analisis Daya Dukung Pondasi Bore Pile Pada Proyek Pembangunan Gedung Wahid Hasyim Apartmen Medan. Medan: Universitas Medan Area.

[6] Hardiyatmo, H. C. (2010). Mekanik Tanah II. (Edisi Ketiga). Yogyakarta : Gadja Mada University Press.

[7] Hardiyatmo, H. C. (2014). Analisis dan Perancangan Fondasi I. (Edisi Ketiga). Yogyakarta : Gadjah Mada University Press. 
[8] Hardiyatmo, H. C. (2015). Analisis dan Perancangan Fondasi II. (Edisi Ketiga). Yogyakarta : Gadjah Mada University Press.

[9] Kim, S. (2017). Pile Foundation Design Through the Increased Bearing Capacity of Extended End Pile. Journal of Asian Architecture and Building Engineering, 05 : 402.

[10] Nur, P. A. (2019). Studi Perencanaan Pondasi Tiang Bor (Bored Pile) Pada Gedung Transmart Malang. Malang: Institut Teknologi Nasional Malang.

[11] Ramadhon, G. (2020). Analisis Daya Dukung dan Penurunan Pondasi Tiang Pancang pada Proyek Pembangunan Gedung DPRD Kabupaten Pemalang. Banyumas: Universitas Muhammadiyah Purwokerto.

[12] Sardjono, H. S. (1988). Pondasi Tiang Pancang. (Jilid I). Surabaya : Sinar Jaya Wijaya.

[13] Yuliawan, E. (2018). Analisis Daya Dukung dan Penurunan Pondasi Tiang Berdasarkan Pengujian SPT dan Cyclic Load Test. Jurnal Kontruksi, vol 9.2. 
